\section{Early Childhood Development: The Buzz Word in Child Health Today}

\author{
Nandita Chattopadhyay* \\ Professor of Paediatrics, IQ City Medical College, Durgapur, India
}

\begin{abstract}
Early Childhood is the foundation of future life. Healthy development in the first few years of life provide building blocks for educational achievement, emotional stability and morality in individuals to make them responsible citizens, together building strong communities. From conception to 3 years of age, brain development progresses at a fabulous rate. Total brain volume doubles in the $1 \mathrm{st}$ yr of life and attains $72 \%$ of adult size. By 3 years the brain has more than 100 billion neurons and each neuron develops on an average 15,000 synapses.

This prolific brain development is dependent on numerous biological and environmental factors, which include genetic constitution, physical health, nutrition, psychomotor stimulation, proper parenting and family support etc. Poverty, neglect, abuse, wars, famines etc have definite derogatory effect.

In the developing world, even today, 250 million children fail to meet cognitive developmental potential in 1 st 5 years of life. Promotion of early childhood development calls for a holistic socio-medical movement, with multiple stake-holders and parents at the pivotal position.
\end{abstract}

Keywords: Early childhood development; Nurturing care; Parental skills; Psychomotor stimulation; Resilience; Toxic stress

\section{Introduction}

\section{What is early childhood development?}

Development of a child is a process of evolution from immature to mature, from a state of no control to full control, over self and over

*Corresponding author: Nandita Chattopadhyay, Professor of Pediatrics, IQ City Medical College, Durgapur, India, Tel: +91 9674905780; Email: chattnan@ gmail.com

Citation: Chattopadhyay N (2019) Early Childhood Development: The Buzz Word in Child Health Today. J Community Med Public Health Care 6: 061.

Received: November 8, 2019; Accepted: December 5, 2019; Published: December 12, 2019

Copyright: @ 2019 Chattopadhyay N. This is an open-access article distributed under the terms of the Creative Commons Attribution License, which permits unrestricted use, distribution, and reproduction in any medium, provided the original author and source are credited. the environment. This is a continuous process from conception to maturity but the velocity of development peaks during the 1st few years of life. This is referred to as Early Childhood Development.

During these early years development occurs at an exponential rate in all domains, which include Motor (Gross \& Fine), Cognitive, Language, Social \& Emotional. This critical period from conception to the start of school provides a critical window of opportunity to shape the development of a child's brain, leading to a favorable outcome.

\section{Why is ECD so relevant today?}

Early Childhood is the foundation of future life. A child who is healthy and well-nourished, who is growing to his full potential and is achieving developmental milestones in all domains adequately, in proper time, who is growing up in a loving, supportive environment with proper psycho-social stimulation, will grow up into a healthy, balanced, stable, well-functioning individual, ready to face life and achieve his best. Such persons will build a healthy, prospering society. Thus, to quote UNICEF, "Early childhood development is the key to a full and productive life for a child and to the progress of a nation".

With improved healthcare in the last few decades, perinatal, infant and under-5 mortality have come down significantly. Global statistics shows a 53\% drop from 1990 to 2015 in childhood mortality. Childhood illness and morbidity has also decreased drastically. But, unfortunately, many of the surviving children are not reaching their developmental potential. In the developing world, even today, 250 million children ( $43 \%$ of child population) fail to meet cognitive developmental potential in 1 st 5 years of life $[1,2]$.

Healthy development in the first few years of life provides building blocks for educational achievement as well as emotional stability and morality. This leads to better economic productivity of the individual in adulthood and they grow up into responsible citizens, together building strong communities. It has been shown that an increased adult income in the new generation can break the intergenerational cycle of poverty and raise the human capital [2]. These educated youngsters will also be the successful parents of the next generation.

All this will fail to be achieved if we do not focus on early childhood development in time. A study from the economic point of view shows that the cost of inaction today predicts a loss of $26 \%$ adult income/year. Can we afford to ignore this burning issue?

\section{Neurobiology of development}

A study of the neuro-biology of the developing brain also demonstrates the importance of the early years in brain development.

From conception to 3 years of age, brain development progresses at a fabulous rate. Total brain volume doubles in the 1 st year of life and increases by an additional $15 \%$ over the 2 nd year. Total brain volume at age 1 month is approximately $36 \%$ of adult volume whereas by age 1 year it is approximately $72 \%$ [3]. 
In the first year of life, the neurons form new connections at the astounding rate of upward from 1000 per second [4]. An overproduction of neuronal precursors eventually leads to about 100 billion neurons and each neuron develops on an average 15,000 synapses by 3 years of age. This 'overgrowth' is sized down as the synapses are pruned back substantially and new connections are made, largely as a result of experience. Synapses in frequently used pathways are preserved, whereas less-used ones atrophy. Changes in the strength and number of synapses and reorganization of neuronal circuits play important roles in brain plasticity. Periods of behavioral development are generally marked by great changes in synaptic numbers in relevant areas of the brain.

The plasticity of the brain continues into adolescence, with further development of the prefrontal cortex, which is important in decision-making, future planning, and emotional control.

The preschool brain experiences dramatic changes in its anatomical and physiologic characteristics. There is increase in cortical area, decreases in cortical thickness, and changing cortical volume. Gray and white matter tissue properties like diffusion in the cerebral fibre tracts change dramatically and increase in metabolic demands of the brain is noted. The 'scaffolding' in younger children is discarded as they grow up. The preschool brain is characterized by growth and expansion that will be followed in later years by pruning.

Brain architecture and function builds from bottom up. Simpler skills are attained first, based on which newer and finer skills are learnt. So, if the fundamental knowledge and skills are inadequate, finer skills will eventually falter. For example, early fine motor skills like handling and manipulating small toys form the basis for good pencil grip and early writing skills.

Many psychiatric and developmental disorders are thought to result at least in part from disruptions in the functional connectivity of brain networks. Functional MRI studies have demonstrated such disruptions.

As brain development progresses a dynamic and continuous interaction between biology and experience continues (Transactional model).

\section{Factors Affecting ECD}

As the fetus grows in utero and a newborn grows up in the first few years, numerous factors come into play to influence this growth, of which some are biological factors, some environmental [5]. Some are risk factors while others are protective factors (Figure 1).

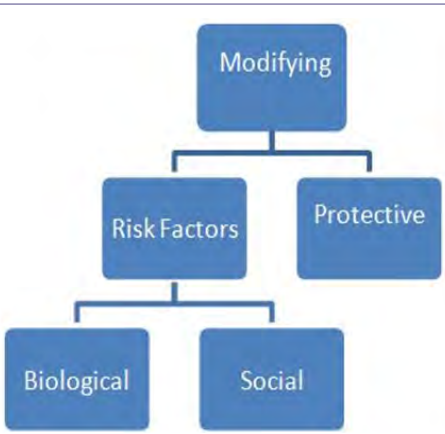

Figure 1: Factors affecting ECD.

\section{Risk factors may be enumerated as}

- Neonatal risk factors

- Genetic disorders

- Poor nutrition

- Illness

- Lack of stimulation

- Poor parenting

- Neglect/abuse

- Poverty, etc.

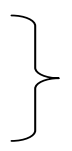

Biological factors

\section{Protective factors include}

- Breast feeding

- Family support

- Resilience

- Peer interaction

\section{Biological factors}

Biologic influences on development include genetics, in utero exposure to teratogens, perinatal insult to the developing brain like hypoxic damage, the long-term negative effects of low birth-weight and prematurity, postnatal illnesses like hypoglycemia, sepsis and meningitis, exposure to hazardous substances like lead and mercury, inborn errors of metabolism and many more systemic derangements. Any chronic illness can affect growth and development, either directly or through changes in nutrition, parenting, or peer interactions. Both stress and reproductive hormones also affect brain development and behavior. Heredity accounts for approximately $40 \%$ of the variance in intelligence and in other personality traits, such as sociability. Maternal prenatal stress and anxiety is associated with the child's temperament, possibly through stress hormones $[5,6]$.

\section{Environmental factors}

It is evident that environmental factors play a major role in early development of a child. Genes provide the blueprint while environment gives final shape to the brain [5,7].

Lack of psychomotor stimulation, poverty, poor parenting, neglect and abuse are crucial factors affecting the child's development. Development of synapses and association fibers depend on the amount of stimuli received by the child and the opportunity he gets to respond to the stimuli. The child learns by responding to an internalized logic of cause and effect. A particular response from a child is strengthened when the cue he gives is responded to effectively and consistently. This is referred to as the 'serve and return' principle of learning [8].

This learning process is dependent on the plasticity of the brain. A child deprived of adequate stimulation will falter in acquiring skills, as neuronal associations will fail to develop adequately. Development occurs from bottom upwards [8], difficult skills build up on stable attainment of simpler skills. For example, a baby with a good pincer grasp will develop a pencil grip faster. For a child denied an exposure to play with small articles may eventually falter in gripping a pencil correctly. Parents play the pivotal role in early childhood development. Their inability to provide a stimulating environment will hinder the child's development. Apart from that, various maternal factors like mother's physical and mental health, her education, adolescent 
parenting, unwanted pregnancy, inadequate birth spacing and consanguinity have all been linked to poor developmental outcome.

Poverty affects a child's development in many ways. Poor nutrition, illness, inadequate home environment, parental neglect may all be results of poverty and each of them are risk factors for poor development.

Stressful situations, in the family or society like negligence, physical or mental abuse, exposure to family discordance, war or famine may lead to toxic stress [8-10]. Toxic stress response occurs when a child experiences strong, frequent, and/or prolonged adversity without adequate adult support.

This, in turn, can bring about epigenetic changes such as DNA methylation and his tone acetylation, leading to alterations in gene expression, hence altered brain structure and function and disruption of later coping mechanisms $[11,12]$. These changes not only affects the child's own development, but may be carried forward into the next generation too.

Environmental factors may be protective as well. Some common examples are breast feeding, family support, resilience and peer interaction. Breastfeeding provides not only nutrition but solace and comfort which is congenial for cognitive development and emotional stability. Mild stress, like small failures and temporary deprivations help build a resilience which makes the child emotionally more stable and stronger. Such stress factors may be simple things like losing in a game, facing parental restrictions or experiencing short term separation from the primary care-giver (when mother goes to office). With severe but short-term stress such as death of a family member or separation, the presence of a caring family member can protect the child and help in coping, thereby preventing developmental problems. The personal histories of children who overcome poverty or toxic stress often include the presence of a trusted adult (parent, grandparent, teacher) with whom the child has a special, supportive, close relationship. Overall, nurturing care [13], from the immediate environment promotes development in a child and helps him attain the best of his potentiality. Nurturing care is characterized by a stable environment that promotes children's health and nutrition, protects children from threats, and gives them opportunities for early learning, through affectionate interactions and relationships [13].

It is evident that an intricate interplay of genetics, health and environment leads to the final neuro-developmental outcome of a child. With the advances in neurology, genomics including epigenetics, molecular biology and the social sciences, an eco-bio developmental framework [3] has emerged, emphasizing on this intricate blending. The transactional model [3] of development proposes that a child's status at any point in time is a function of the interaction between biologic and social influences and these influences are bidirectional Biologic factors like poor health may affect the child-rearing environment. A premature infant may cry little and sleep for long periods, which may lead to poor nutrition and inadequate growth. This child may tend to be neglected, with more vigorous, demanding children in the family. When parent-child interactions are optimal, prematurity carries a reduced risk of developmental disability.

When early intervention programs provide timely, intensive, comprehensive, and prolonged services, at-risk children show marked and sustained up-swings in their developmental trajectory.
Early identification of children at developmental risk, along with early intervention to support parenting, is critically important.

\section{Life cycle approach to developmental risk factors}

Risk factors operating at different stages of life can affect ECD of that individual or his/her offspring's development. Hence, the factors need to be addressed at all stages of life (Figure 2).

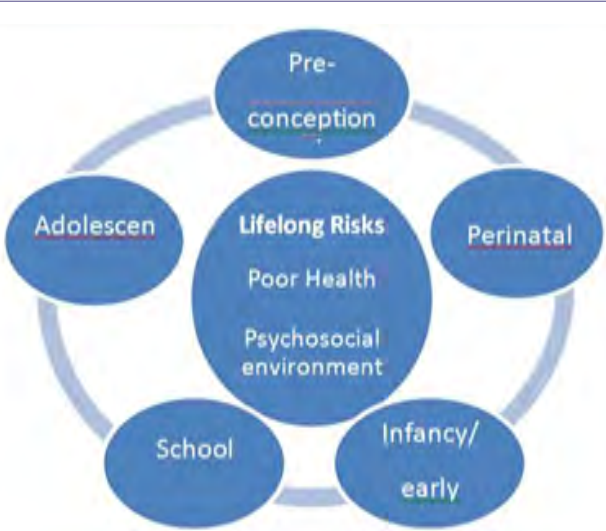

Figure 2: Life cycle approach to developmental risk factors.

Comparing the impact of biological factors on a child's development with that of social factors, we can conclude that the former affect fewer children but the impact is generally more severe leading to well defined developmental challenges which call for specific diagnostics and treatment and institutional management. Common examples are genetic disorders, congenital anomalies or neonatal insult to the brain as in HIE.

On the other hand, social factors affect larger populations, often whole communities. Children with a biological potential to develop normally, do not attain their potential due to social hindrances. What we find are mild delays or aberrations in development with cognitive or socio-emotional impairment. These cases, though numerous, are preventable and interventions are simple and home based or community based.

\section{What needs to be done to Augment Development?}

Promotion of early childhood development calls for a holistic socio-medical movement, where multiple stake-holders have to join hands. At the pivotal position are the parents, who are to be supported by the medical fraternity and educationists. Social activist bodies, non-profits, government agencies, global welfare agencies, all need to join hands to promote this very important agenda.

The vital role of parents in a child's development is indubitable. Parents influence a child's development in numerous ways, right from the moment of conception. The mother's physical and mental health both affects the growth of a fetus. A sick mother will not be able to nurture her child adequately. Maternal depression has been shown to adversely affect the child's emotional development. Parental, particularly maternal education has been shown to strongly influence a child's cognitive development. Provision of nurturing care, proper psychomotor stimulation, positive parenting are all fine tuned parenting skills which go a long way to promote a child's development. 
For this, is required a healthy family environment, parental education and maturity. Adolescent mothers with unwanted pregnancies or inadequate spacing between children is liable to result in improper child care and stimulation, hence ECD will suffer.

Firstly awareness about ECD and nurturing care needs to be generated among parents and field level workers. They need to be motivated to deliver proper health care, nutrition and psychomotor stimulation to the child. Emphasis needs to be laid on parenting skills and home-based intervention. Unfortunately, knowledge, skill and awareness regarding a child's development, signs of delay, and early intervention methods is grossly lacking among the grass-root level health workers in most developing countries. A WHO survey has revealed that home based health care services, though free, do not reach more than $50 \%$ population in the Low Middle Income Group (LMIG) countries and healthcare providers lack adequate training \& experience in prevention, early detection and early intervention, they are mostly not trained to use any standardized tool for detection [5].

Here comes in a word of caution. Uniform delivery of services at the grass-root level is easier said than done. It requires a huge amount of planning, program setting and feasibility studies from the policy-makers and implementing agencies [14]. Each community has its own focus areas in ECD and its own problems in implementation, but for none is it an easy task. It requires delivery of a highly refined and technical skill in a very down-to-earth, doable manner, made available to all children. The service providers must have adequate training and skills and access to supportive supervision and referral service.

It is high time now, that we all put our efforts together to come up with the right deliverables so our children today grow up to build a better tomorrow.

\section{Conclusion}

Early Childhood Development is a global issue and needs to be addressed by every community. Health, education, economics and social support need to be addressed simultaneously through wellplanned strategies and a comprehensive service delivery system is required to reach out to every single family. We need to put our efforts together to come up with the right deliverables for nurturing care so our children today grow up to build a better tomorrow.

\section{Conflict of Interest: None}

\section{References}

1. Lu C, Black MM, Richter LM (2016) Risk of poor development in young children in low-income and middle-income countries: an estimation and analysis at the global, regional, and country level. The Lancet Glob Health 4: $916-922$.
2. Black MM, Walker SP, Fernald LCH, Andersen CT, DiGirolamo AM, et al. (2017) Early childhood development coming of age: science through the life course. Lancet 389: 77-90.

3. Kliegman RM, Stanton BF, St Geme III JW, Schor NF (2016) Nelson textbook of pediatrics (20thedn). In: Behrman RE (eds.). Assessment of Fetal Growth and Development. Elsevier, London, UK. Pg no: 60-61.

4. Nelson CA (2000) The neurobiological bases of early intervention. In Handbook of Early Childhood Intervention ( $2^{\text {nd }}$ ed. JP Shonkoff \& SJ Meisels, Eds: 204-227). Cambridge, MA: Cambridge University Press, Cambridge, UK.

5. World Health Organization (2012) Developmental Difficulties in Early Childhood. WHO, Geneva, Switzerland.

6. Kliegman RM, Stanton BF, St Geme III JW, Schor NF (2016) Nelson textbook of pediatrics $\left(20^{\text {th }}\right.$ edn). In: Behrman RE (eds.). Cognitive Development Domains and Theories. Elsevier, London, UK. Pg no: 54-59.

7. Britto PR, Singh M, Dua T, Kaur R, Yousafzai AK, et al. (2018) What implementation evidence matters: scaling-up nurturing interventions that promote early childhood development. Ann N Y Acad Sci 1419: 5-16.

8. Shonkoff JP, Boyce WT, Cameron J, Duncan G, Fox NA, et al. (2007) The Science of Early Childhood Development. National Scientific Council on the Developing Child Pg no: 1-16.

9. Shonkoff JP (2016) Capitalizing on Advances in Science to Reduce the Health Consequences of Early Childhood Adversity. JAMA Pediatr 170: 1003-1007.

10. Shonkoff JP, Garner AS; Committee on Psychosocial Aspects of Child and Family Health; Committee on Early Childhood, Adoption, and Dependent Care; Section on Developmental and Behavioral Pediatrics (2012) The lifelong effects of early childhood adversity and toxic stress. Pediatrics 129:232-46.

11. McCain MN, Mustard JF, Shanker S (2007) Early Years Stud 2: Putting Science into Action. Council for Early Child Development, Ontario, Canada. Pg no: 1-178.

12. Mehler MF (2008) Epigenetics in the nervous system. Annals of Neurology 64: 602-617.

13. Britto PR, Lye SJ, Proulx K, Yousafzai AK, Matthews SG, et al. (2017) Nurturing care: promoting early childhood development. Lancet 389: 91102 .

14. Shawar YR, Shiff J (2017) Generation of global political priority for early childhood development: the challenges of framing and governance. Lancet 389: 119-124. 


\section{II}

Journal of Anesthesia \& Clinical Care

Journal of Addiction \& Addictive Disorders

Advances in Microbiology Research

Advances in Industrial Biotechnology

Journal of Agronomy \& Agricultural Science

Journal of AIDS Clinical Research \& STDs

Journal of Alcoholism, Drug Abuse \& Substance Dependence

Journal of Allergy Disorders \& Therapy

Journal of Alternative, Complementary \& Integrative Medicine

Journal of Alzheimer's \& Neurodegenerative Diseases

Journal of Angiology \& Vascular Surgery

Journal of Animal Research \& Veterinary Science

Archives of Zoological Studies

Archives of Urology

Journal of Atmospheric \& Earth-Sciences

Journal of Aquaculture \& Fisheries

Journal of Biotech Research \& Biochemistry

Journal of Brain \& Neuroscience Research

Journal of Cancer Biology \& Treatment

Journal of Cardiology: Study \& Research

Journal of Cell Biology \& Cell Metabolism

Journal of Clinical Dermatology \& Therapy

Journal of Clinical Immunology \& Immunotherapy

Journal of Clinical Studies \& Medical Case Reports

Journal of Community Medicine \& Public Health Care

Current Trends: Medical \& Biological Engineering

Journal of Cytology \& Tissue Biology

Journal of Dentistry: Oral Health \& Cosmesis

Journal of Diabetes \& Metabolic Disorders

Journal of Dairy Research \& Technology

Journal of Emergency Medicine Trauma \& Surgical Care

Journal of Environmental Science: Current Research

Journal of Food Science \& Nutrition

Journal of Forensic, Legal \& Investigative Sciences

Journal of Gastroenterology \& Hepatology Research

Journal of Gerontology \& Geriatric Medicine
Journal of Genetics \& Genomic Sciences

Journal of Hematology, Blood Transfusion \& Disorders

Journal of Human Endocrinology

Journal of Hospice \& Palliative Medical Care

Journal of Internal Medicine \& Primary Healthcare

Journal of Infectious \& Non Infectious Diseases

Journal of Light \& Laser: Current Trends

Journal of Modern Chemical Sciences

Journal of Medicine: Study \& Research

Journal of Nanotechnology: Nanomedicine \& Nanobiotechnology

Journal of Neonatology \& Clinical Pediatrics

Journal of Nephrology \& Renal Therapy

Journal of Non Invasive Vascular Investigation

Journal of Nuclear Medicine, Radiology \& Radiation Therapy

Journal of Obesity \& Weight Loss

Journal of Orthopedic Research \& Physiotherapy

Journal of Otolaryngology, Head \& Neck Surgery

Journal of Protein Research \& Bioinformatics

Journal of Pathology Clinical \& Medical Research

Journal of Pharmacology, Pharmaceutics \& Pharmacovigilance

Journal of Physical Medicine, Rehabilitation \& Disabilities

Journal of Plant Science: Current Research

Journal of Psychiatry, Depression \& Anxiety

Journal of Pulmonary Medicine \& Respiratory Research

Journal of Practical \& Professional Nursing

Journal of Reproductive Medicine, Gynaecology \& Obstetrics

Journal of Stem Cells Research, Development \& Therapy

Journal of Surgery: Current Trends \& Innovations

Journal of Toxicology: Current Research

Journal of Translational Science and Research

Trends in Anatomy \& Physiology

Journal of Vaccines Research \& Vaccination

Journal of Virology \& Antivirals

Archives of Surgery and Surgical Education

Sports Medicine and Injury Care Journal

International Journal of Case Reports and Therapeutic Studies

Journal of Ecology Research and Conservation Biology

Submit Your Manuscript: http://www.heraldopenaccess.us/Online-Submission.php 